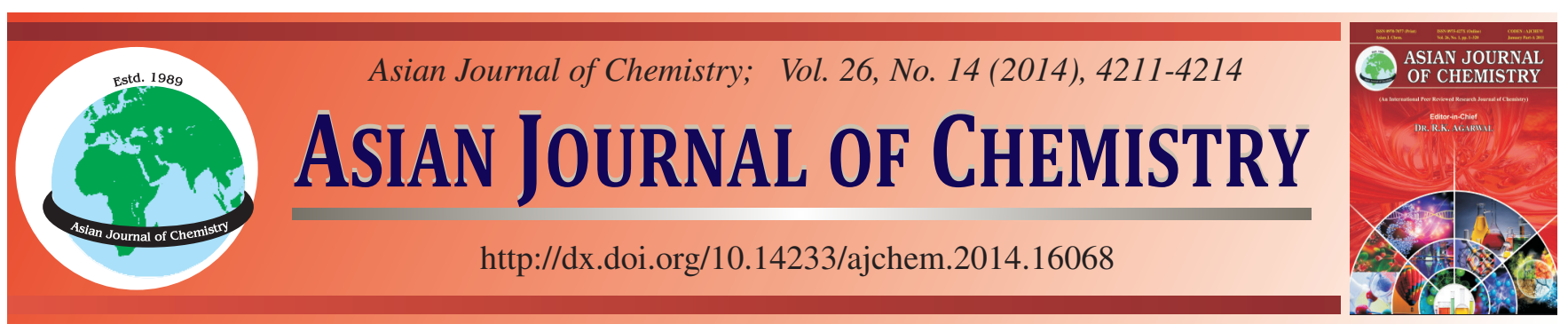

\title{
Debromination of Bromobenzene Induced by Hydrated Electrons in Aqueous Solution
}

\author{
Haixia Yuan ${ }^{1,2}$, HuXiang Pan ${ }^{2}$, Jin Shi ${ }^{1}$, Honguing Li $I^{1, *}$ and Wenbo Dong ${ }^{1, *}$
}

${ }^{1}$ Shanghai Key Laboratory of Atmospheric Particle Pollution and Prevention, Department of Environmental Science and Engineering, Fudan University, Shanghai 200433, P.R. China

${ }^{2}$ Institutes of Naval Medicine, Shanghai 200433, P.R. China

*Corresponding authors: Tel/Fax: +86 21 65642030; E-mail: lihongjing@ fudan.edu.cn; wbdong@fudan.edu.cn

Keywords: Laser flash photolysis, Hydrated electrons, Bromobenzene, Anion radicals.

\section{INTRODUCTION}

Halogenated aromatic carbons (HACs) are important organic chemical raw materials, which are widely used for pesticides, pharmaceuticals, material synthesis, etc. They have been found in gases, smoke, airborne particles, surface and drinking waters, soils and sediments ${ }^{1-5}$. The majority of these compounds are chlorinated and brominated. They are confirmed to have significant toxicological effects in liver, kidney and even the central nervous system of human ${ }^{6,7}$. Hydrated electron addition to halogenated aromatic carbons is known to liberate halogen ion by dissociative electron capture process due to the high electron affinity of the halogen ${ }^{8,9}$. In the literature, there were some studies concerning the reaction between hydrated electrons and halogenated aromatic compounds. Lichtsdcheidl and Getoff ${ }^{10}$ demonstrated that the primary reaction pathway of halobenzene with hydrated electrons was gradual dehalogenation. Naik and Mohan ${ }^{9}$ confirmed that dehalogenation would be more easily when the radius of halogen substitution was larger and the electron affinity was stronger ${ }^{9}$. Higashino et al. ${ }^{11}$ reported that the characteristic absorption spectra of fluorobenzene anion radicals lied in the ranges of 300-500 $\mathrm{nm}$ by radiolytic degradation experiments and time-dependent density functional theory (TD-DFT). However, less is known about the kinetic of hydrated electrons attachment to bromobenzene and the structure of the anion radical.
In this study, layer flask photolysis (LFP) experiments were adopted to investigate the kinetics of the reaction between bromobenzene and hydrated electrons in aqueous solution. The optimal structure of bromobenzene anion radicals, the bond lengths and bond angles were calculated and analyzed by timedependent density functional theory (TD-DFT)-UB3LYP method. The final products were determined by gas chromatographymass spectrometry (GC-MS) and ion chromatography (IC).

\section{EXPERIMENTAL}

Bromobenzene was of chromatographic purity (> 99\%) and purchased from J\&K Technology Co., Ltd.; Pyrenetetrasulfonate (PyTS) was of chromatographic purity ( $\geq 98.0 \%)$ and purchased from Sigma-Aldrich; High-purity $\mathrm{N}_{2}(99.999 \%)$ was purchased from Shanghai Biou xi Gas Industry Co.. All experimental aqueous solutions were prepared with deionized water and pre-saturated with $\mathrm{N}_{2}$.

Experimental instruments and methods: The layer flask photolysis was carried out with a Quanta Ray LAB-150-10 Nd: YAG laser and the excitation wavelength was $355 \mathrm{~nm}$. The details of layer flask photolysis were described previously ${ }^{12}$. The laser pulse energy was measured by a Nova PE25BB-SH-V2 pyroelectric head (Ophir Optronics Ltd.). The sample was placed in the $1 \times 1 \mathrm{~cm}$ quartz cuvette. All the experiments were performed under the temperature $25^{\circ} \mathrm{C} \pm 1^{\circ} \mathrm{C}$. To avoid secondary 
photolysis of the sample by the analyzing light, suitable filters were employed.

Gas chromatography (7890A, Agilent, USA) coupled with a mass spectrometry (5975C, Agilent, USA) (GC-MS) was performed to identify the degradation products. GC-MS was equipped with a DB-5 MS column $(30 \mathrm{~m} \times 0.25 \mathrm{~mm} \times 0.25$ $\mu \mathrm{m})$. Helium was used as the carrier gas at a constant flow rate of $1 \mathrm{~mL} \mathrm{~min}^{-1}$. The $\mathrm{GC}$ temperature program was $60{ }^{\circ} \mathrm{C}$ (hold for $5 \mathrm{~min}$ ) to $280{ }^{\circ} \mathrm{C}$ (hold for $10 \mathrm{~min}$ ) at $5{ }^{\circ} \mathrm{C} \mathrm{min}^{-1}$. Both injection and ion source temperature were $250^{\circ} \mathrm{C}$. Before GC-MS analysis, $50 \mathrm{~mL}$ irradiated samples were extracted by $5 \mathrm{~mL}$ dichloromethane.

The concentration of $\mathrm{Br}$ - generated from bromobenzene degradation was determined by IC, which consisted of a hydrophilic anion exchange column and an autosampler. A Dionex IonPac AS1 1 column $(2 \times 250 / 4 \times 250 \mathrm{~mm})$ and the eluent of $10 \mathrm{mM} \mathrm{KOH}$ at a flow rate of $0.33 \mathrm{~mL} \mathrm{~min}^{-1}$ were employed. Injection volume was $10 \mathrm{~mL}$.

Calculation method: Density functional theory (DFT)UB3LYP method in combination with the $6-31+\mathrm{G}(\mathrm{d}, \mathrm{p})$ basis sets were used to obtain the structure and the optical properties (absorption peak and oscillator strength) of anion radical. All calculations were performed by a Gaussian 09 software package.

\section{RESULTS AND DISCUSSION}

Production of hydrated electrons: The laser flash photolysis of $9.83 \times 10^{-5} \mathrm{M}$ PyTS in $\mathrm{N}_{2}$ saturated aqueous solution was performed and two-photon ionization process of PyTS occurred, which led to the formation of triplet PyTS ( ${ }^{3}$ PyTS), cation radicals $\left(\mathrm{PyTS}^{+\cdot}\right)$ and hydrated electrons ${ }^{12,13}$. The absorption bands of ${ }^{3} \mathrm{PyTS}$ and $\mathrm{PyTS}^{+\cdot}$ were at $<500 \mathrm{~nm}$ (the absorption peak of the former was at $430 \mathrm{~nm}$, the latter 510 $\mathrm{nm})$. The broad and irregular absorption at 550-750 nm was attributed to the characteristic absorption of hydrated electrons (peak at around $700 \mathrm{~nm}$ ). That is, the absorption at $690 \mathrm{~nm}$ was mainly caused by hydrated electrons and less interfered by other transient absorptions. Therefore, the kinetics of the reaction between hydrated electrons and bromobenzene in solution was analyzed based on the absorption changes at this particular wavelength.

\section{Kinetics analysis of the reaction}

Rate constant of first-order reaction: Based on the hydrated electrons absorbance at this wavelength $(\lambda=20560$ $\left.\mathrm{mol} \mathrm{L} \mathrm{cm}^{-1}\right)^{14}$, the concentration of hydrated electrons at the initial time of the reaction could be calculated as $3.8 \times 10^{-6}$ mol L $\mathrm{L}^{-1}$. There were mainly three reactions where hydrated electrons were involved, as shown in eqns. (1), (2). In the solution, the concentrations of bromobenzene $\left(4.2 \times 10^{-5} \mathrm{~mol}\right.$ $\left.\mathrm{L}^{-1}\right)$ and pyrenetetrasulfonate (PyTS) in rate constant of firstorder reaction $\left(9.8 \times 10^{-5} \mathrm{~mol} \mathrm{~L}^{-1}\right)$ were much greater than the concentration of hydrated electrons. Therefore, the eqns. (2) and (3) could be approximated to first-order reaction. Therefore, it could be seen that the decay of hydrated electrons was consistent with one second-order reaction and two quasi firstorder reactions.

$$
\mathrm{e}_{\mathrm{aq}}^{-}+\mathrm{e}_{\mathrm{aq}}^{-} \underset{\mathrm{k}_{1}}{\stackrel{2 \mathrm{H}_{2} \mathrm{O}}{\longrightarrow}} \mathrm{H}_{2}+2 \mathrm{OH}^{-}
$$

$$
\begin{aligned}
& \mathrm{e}_{\mathrm{aq}}^{-}+\mathrm{BrB} \stackrel{\mathrm{k}_{2}}{\longrightarrow} \text { Product } \\
& \mathrm{e}_{\mathrm{aq}}^{-}+\mathrm{PyTS}^{\longrightarrow} \stackrel{\mathrm{k}_{3}}{\longrightarrow} \text { pyTS }^{\circ}
\end{aligned}
$$

In summary, the concentration change of hydrated electrons in the solution was in agreement with eqn. (1):

$$
\begin{gathered}
-\frac{\mathrm{d}\left[\mathrm{e}_{\mathrm{aq}}^{-}\right]}{\mathrm{dt}}=\mathrm{k}_{1}\left[\mathrm{e}_{\mathrm{aq}}^{-}\right]^{2}+\mathrm{k}_{2}\left[\mathrm{e}_{\mathrm{aq}}^{-}\right][\mathrm{BrB}]+\mathrm{k}_{3}\left[\mathrm{e}_{\mathrm{aq}}^{-}\right][\text {PyTS }] \\
-\frac{\mathrm{d}\left[\mathrm{e}_{\mathrm{aq}}^{-}\right]}{\mathrm{dt}}=\mathrm{k}_{1}\left[\mathrm{e}_{\mathrm{aq}}^{-}\right]^{2}+\mathrm{k}_{2}{ }^{\prime}\left[\mathrm{e}_{\mathrm{aq}}^{-}\right]+\mathrm{k}_{3}{ }^{\prime}\left[\mathrm{e}_{\mathrm{aq}}^{-}\right]
\end{gathered}
$$

After integrating eqn. (2), the concentration change of hydrated electrons was obtained, as shown in eqn. (3):

$$
\left(\mathrm{e}_{\mathrm{aq}}^{-}\right)=\frac{\left(\mathrm{k}_{2}^{\prime}+\mathrm{k}_{3}^{\prime}\right)\left[\mathrm{e}_{\mathrm{aq}}^{-}\right]_{0} \mathrm{e}^{-\left(\mathrm{k}_{2}^{\prime}+\mathrm{k}_{3}^{\prime}\right)}}{\mathrm{k}_{1}\left[\mathrm{e}_{\mathrm{aq}}^{-}\right]_{0}\left(1-\mathrm{e}^{-\left(\mathrm{k}_{2}^{\prime}+\mathrm{k}_{3}^{\prime}\right) \mathrm{t}}\right)+\left(\mathrm{k}_{2}^{\prime}+\mathrm{k}_{3}^{\prime}\right)}
$$

Take $\mathrm{A}_{\mathrm{t}}\left(\mathrm{e}_{\mathrm{aq}}^{-}\right)=\varepsilon c \mathrm{into}$ eqn. (3) to obtain the absorbance change of hydrated electrons in the solution, as shown in eqn. (4).

$$
\mathrm{A}\left(\mathrm{e}_{\mathrm{aq}}^{-}\right)=\frac{\varepsilon \mathrm{l}\left(\mathrm{k}_{2}^{\prime}+\mathrm{k}_{3}^{\prime}\right) \mathrm{A}_{0}\left[\mathrm{e}_{\mathrm{aq}}^{-}\right]_{0} \mathrm{e}^{-\left(\mathrm{k}_{2}^{\prime}+\mathrm{k}_{3}^{\prime}\right) \mathrm{t}}}{2 \mathrm{k}_{1} \mathrm{~A}_{0}\left[\mathrm{e}_{\mathrm{aq}}^{-}\right]\left(1-\mathrm{e}^{-\left(\mathrm{k}_{2}^{\prime}+\mathrm{k}_{3}^{\prime}\right) \mathrm{t}}\right)+\varepsilon l\left(\mathrm{k}_{2}^{\prime}+\mathrm{k}_{3}^{\prime}\right)}
$$

The study conducted by Huang et al. ${ }^{14}$ showed that $\mathrm{k}_{1}=$ $(6.5 \pm 0.2) \times 10^{9} \mathrm{~L} \mathrm{~mol}^{-1} \mathrm{~s}^{-1}$ and $\mathrm{k}_{1}$ was substituted into eqn. (4) and $\mathrm{k}_{2}=(9.7 \pm 0.3) \times 10^{5} \mathrm{~s}^{-1}$ was obtained. The rate constant of the eqn (3) was $(2.7 \pm 0.1) \times 10^{5} \mathrm{~s}^{-1}$, which was studied in our previous research ${ }^{12}$. Therefore the first-order reaction constant of eqn (2) was $(7.0 \pm 0.3) \times 10^{5} \mathrm{~s}^{-1}$ (Fig. 1$)$.

Based on the rate constant of first-order reaction, it can be seen that at the initial time, the ratio of hydrated electrons consumption rate in reaction (1), (2) and (3) was:

$$
\mathrm{k}_{1}\left[\mathrm{e}_{\mathrm{aq}}^{-}\right]: \mathrm{k}_{2}\left[\mathrm{e}_{\mathrm{aq}}^{-}\right][\text {PyTS }]: \mathrm{k}_{3}\left[\mathrm{e}_{\mathrm{aq}}^{-}\right][\mathrm{BrB}]=1: 11: 25.5
$$

Thus, at the initial time, the self-quenching reaction of hydrated electrons took up only a small proportion, while the reactions with bromobenzene and pyrenetetrasulfonate had contributed more greatly to the decay of hydrated electrons, where the rate of reaction with bromobenzene was about two times of that with pyrenetetrasulfonate.

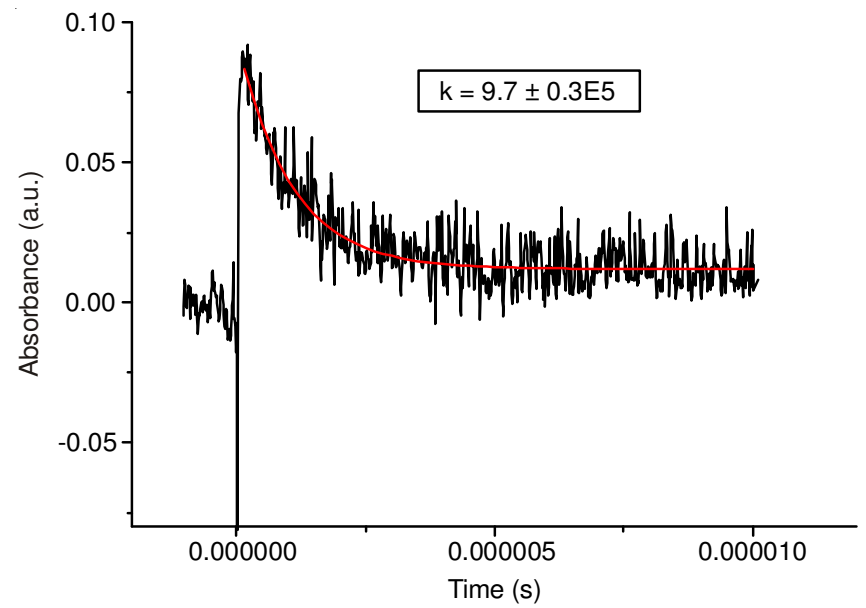

Fig. 1. Decay kinetic of hydrated electrons at $690 \mathrm{~nm}$ 
Rate constant of second-order reaction: Using the calculation method as described, the rate constants of quasi firstorder reaction between bromobenzene and hydrated electrons were obtained under different bromobenzene concentrations $\left(19.8 \times 10^{-5}, 15 \times 10^{-5}, 4.2 \times 10^{-5}, 2.9 \times 10^{-5}\right.$ and $0.8 \times 10^{-5} \mathrm{~mol}$ $\mathrm{L}^{-1}$ ) (Fig. 2). The rate constant of the second-order reaction between bromobenzene and hydrated electrons obtained as $1.7 \times 10^{10} \mathrm{~L} \mathrm{~mol}^{-1} \mathrm{~s}^{-1}$ (shown in Fig. 3) and the findings were basically consistent with the results by Lichtscheidl and Getoff $^{10}$, who employed the radiolytic degradation technology $\left(1.0 \times 10^{10} \mathrm{~L} \mathrm{~mol}^{-1} \mathrm{~s}^{-1}\right)$.

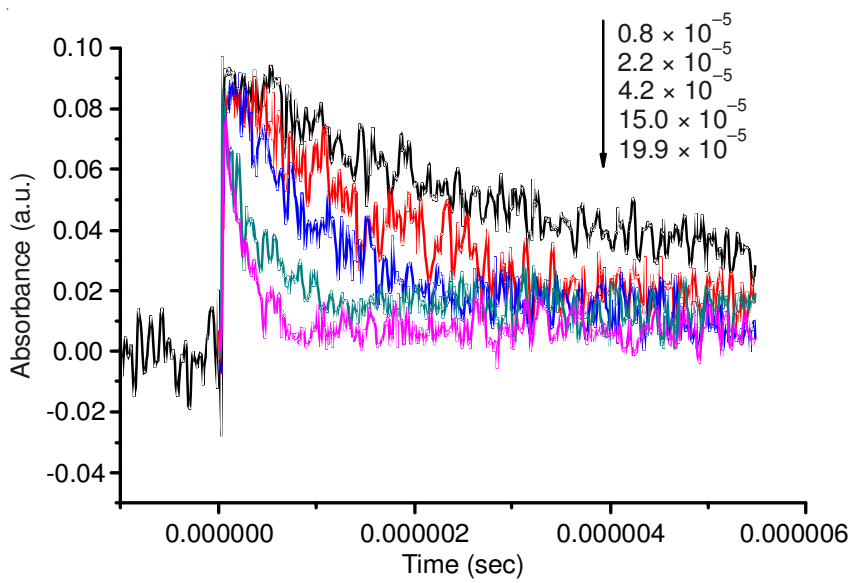

Fig. 2. Decay of hydrated electrons under different bromobenzene concentrations

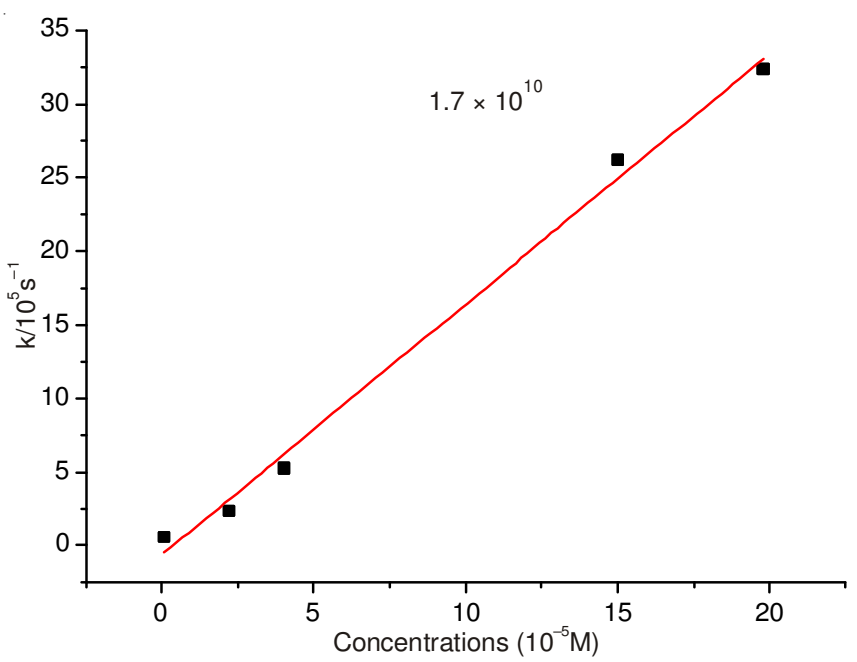

Fig. 3. Fitting of the rate constant of second-order reaction between hydrated electrons and bromobenzene

Analysis of product and reaction pathways: The pyrenetetrasulfonate aqueous solution of bromobenzene was irradiated by $355 \mathrm{~nm}$ laser for $10 \mathrm{~s}$ and extracted to obtain the organic phase using dichloromethane. By using GC-MS detection, the chromatogram was obtained (Fig. 4). Apart from the bromobenzene peak at $5.75 \mathrm{~min}$, unknown peaks at $12.93 \mathrm{~min}$ and 15.53 min were also detected. After analysis using NIST library, the substances corresponding to the two peaks were biphenyl and 2-brominated biphenyl, respectively.

In addition, bromide ions were detected by using ion chromatography after laser flash photolysis and therefore the products of the reaction between bromobenzene and hydrated

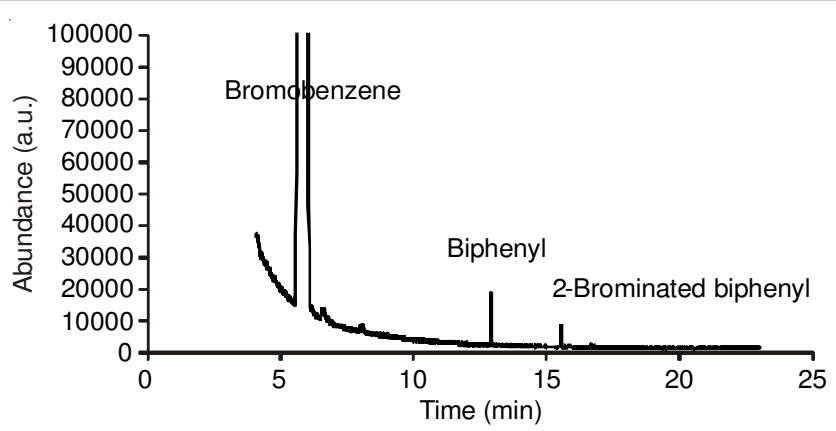

Fig. 4. GC-MS for the PyTS aqueous solution of bromobenzene after 355 $\mathrm{nm}$ laser flash photolysis

electrons were determined as biphenyl, 2-brominated biphenyl and bromide ions. It is probably due to the fact that bromobenzene concentration was greater and the laser energy was higher, hence resulting in a higher concentration of instantaneously generated benzyl radicals. These radicals had selfquenching reactions or reacted with bromobenzene in the solution to generate biphenyl and brominated biphenyl. Wu et al. ${ }^{15}$ showed that when radiolytic degradation occurred in halobenzene aqueous solution with high initial concentration, the instantaneously generated benzyl radicals could also reach a high concentration, generating biphenyl by self-quenching reaction. These were all consistent with our experimental results.

This study showed that debromination reaction occurred when bromobenzene reacting with hydrated electrons and the generated benzyl radicals could further react to generate biphenyl. The reaction pathway was inferred and shown in Fig. 5 (dotted line representing the inference result).

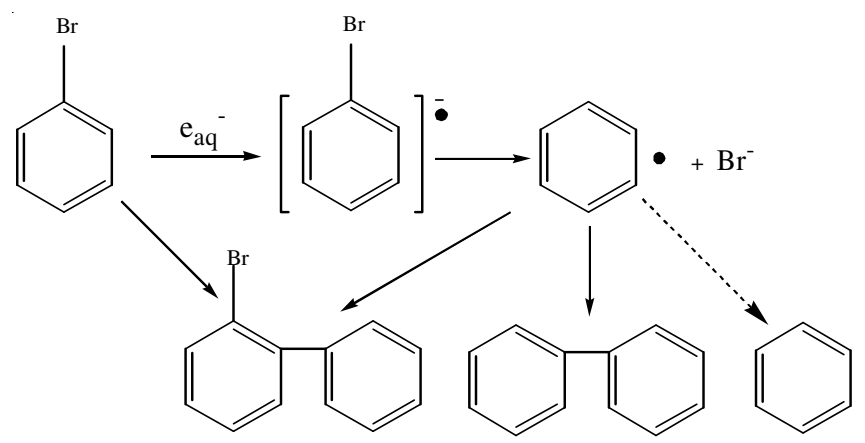

Fig. 5. Reaction pathway of bromobenzene and hydrated electrons

Bromobenzene anion radicals: The reaction mechanism of the hydrated electrons and halogenated aromatics were shown in eqn. (4) and (5): First, electron transfer occurred to hydrated electrons outside of the molecule and they entered the $\pi^{*}$ orbital of lower energy of the halogenated aromatics. Then electron transfer occurred to the $\sigma^{*}$ orbital of $\mathrm{C}-\mathrm{X}$ and thus formed the unstable anion radicals. This reaction was the major step in the chain reaction where aromatic nucleophilic substitution occurred to free radicals ${ }^{16,17}$. Although no absorption spectrum of anion radicals could be seen in the transient absorption spectrum of the laser flash photolysis experiment, we speculate that bromobenzene anion radicals were generated in the course of the reaction. UB3LYP method was used at 6$31+\mathrm{G}(\mathrm{d}, \mathrm{p})$ basis set to optimize the structure of bromobenzene anion radicals (Fig. 6). The bond lengths, bond angles and absorption spectrum characteristics were calculated (Table-1). 


\begin{tabular}{|c|c|c|c|c|c|}
\hline \multicolumn{6}{|c|}{$\begin{array}{c}\text { TABLE-1 } \\
\text { STRUCTURAL PARAMETERS OF BROMOBENZENE ANION RADICALS OPTIMIZED USING 6-31 + G(d,p) BASIS SET }\end{array}$} \\
\hline \multicolumn{3}{|c|}{ Bond lengths $(\AA)$} & \multicolumn{3}{|c|}{ Bond angles $\left({ }^{\circ}\right)$} \\
\hline & Anion radical & Bromobenzene $^{18}$ & & Anion radical & Bromobenzene $^{18}$ \\
\hline $\mathrm{C} 1-\mathrm{C} 2$ & 1.404 & 1.394 & C1-C2-C3 & 119.9 & 118.9 \\
\hline $\mathrm{C} 2-\mathrm{C} 3$ & 1.391 & 1.391 & C2-C3-C4 & 120.4 & 121.5 \\
\hline $\mathrm{C} 3-\mathrm{C} 4$ & 1.391 & 1.391 & C3-C4-C5 & 119.9 & 118.9 \\
\hline C4-C5 & 1.404 & 1.394 & C6-C1-C2 & 120.0 & 120.5 \\
\hline C5-C6 & 1.401 & 1.393 & C6-C1-H7 & 119.8 & 120.2 \\
\hline $\mathrm{C} 1-\mathrm{H} 7$ & 1.090 & 1.085 & C1-C2-H8 & 119.9 & 120.8 \\
\hline $\mathrm{C} 2-\mathrm{H} 8$ & 1.089 & 1.083 & C3-C4-H9 & 120.1 & 120.3 \\
\hline $\mathrm{C} 4-\mathrm{H} 9$ & 1.089 & 1.085 & C4-C5-H10 & 120.1 & 119.3 \\
\hline C5-H10 & 1.090 & 1.085 & C1-C6-H11 & 120.2 & 120.8 \\
\hline C6-H11 & 1.088 & 1.083 & $\mathrm{C} 2-\mathrm{C} 3-\mathrm{Br} 12$ & - & - \\
\hline C3-Br12 & 2.738 & 1.921 & - & - & - \\
\hline
\end{tabular}

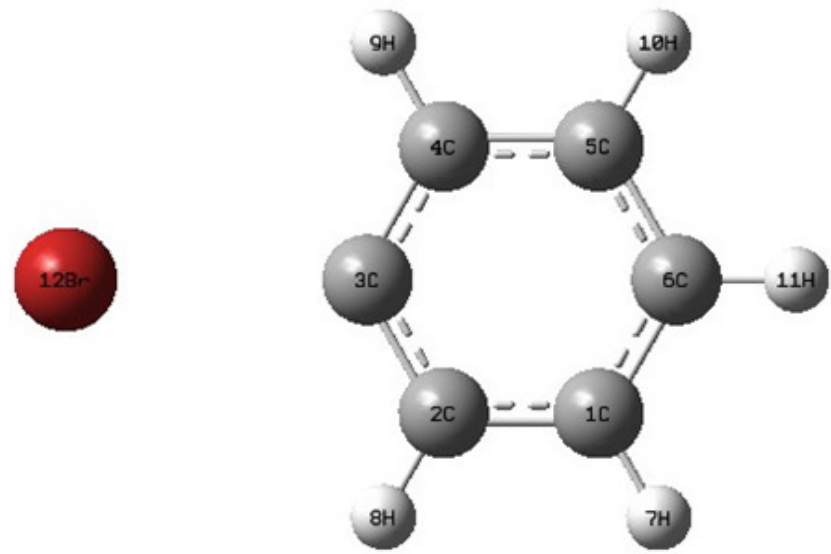

Fig. 6. Optimized structure of bromobenzene anion radicals

$$
\begin{aligned}
& \mathrm{ArX}+\mathrm{e}^{-} \rightarrow \mathrm{ArX}^{-} \\
& \mathrm{ArX}^{-} \rightarrow \mathrm{Ar}^{\circ}+\mathrm{X}^{-}
\end{aligned}
$$

As seen from Table-1, the $\mathrm{C}$-Br bond length of the anion radicals was $2.7381 \AA$, which was significantly lengthened as compared with bromobenzene. This was mainly due to the fact that when the $\sigma^{*}$ bonds of $\mathrm{C}$-Br were attacked by electrons, the electronegativity of $\mathrm{Br}$ was reduced, resulting in weakened covalent bonds and extended bond length. According to the bond angle data, the impact of bromine in anion radicals on benzene ring was reduced and the bromo-substituted C-C-C bond angle changed from $21.5^{\circ}$ in bromobenzene to $20.4^{\circ}$.

It was also found that the absorption band of bromobenzene anion radicals was at $250-600 \mathrm{~nm}$ and the absorption peak appeared at $332 \mathrm{~nm}(\mathrm{f}=0.2703)$. Changes in absorbance at this particular wavelength was not observed during the experiment, suggesting that the $\mathrm{C}$-Br bonds in anion radicals were broken within a very short period of time to form benzyl radicals and bromide ions. Beregovaya and Shchegoleva ${ }^{19}$ believed that electron transfer and dissociation of anion radical were simultaneous and previous results ${ }^{20}$ showed that the electron binding energy of bromobenzene anion radicals was -0.70 , with extremely fast dissociation rate and their life in gas phase was $<10^{-15} \mathrm{~s}$. Therefore, the transient spectrum in nanosecond range was insufficient for the capture.

\section{REFERENCES}

1. W.H. Ding, K.M. Aldous, R.G. Briggs, H. Valente, D.R. Hilker, S. Connor and G.A. Eadon, Chemosphere, 25, 675 (1992).

2. E.M. Boyd, K. Killham, J. Wright, S. Rumford, M. Hetheridge, R. Cumming and A.A. Meharg, Chemosphere, 35, 1967 (1997).

3. S. Masunaga, Y. Yonezawa and Y. Urushigawa, Water Res., 25, 275 (1991).

4. B.G. Oliver, Adv. Chem., 216, 471 (1987).

5. M. Wang and K.C. Jones, J. Agric. Food Chem., 42, 2322 (1994).

6. E. Halfon and M.G. Reggiani, Environ. Sci. Technol., 20, 1173 (1986).

7. M. Julliard, M. Chanon and A. Galadi, J. Photochem. Photobiol. Chem., 83, 107 (1994).

8. H. Mohan and K.-D. Asmus, J. Chem. Soc. Perkin Trans. II, 1795 (1987).

9. D.B. Naik and H. Mohan, Radiat. Phys. Chem., 73, 218 (2005).

10. J. Lichtscheidl and N. Getoff, Int. J. Radiat. Phys. Chem., 8, 661 (1976).

11. S. Higashino, A. Saeki, K. Okamoto, S. Tagawa and T. Kozawa, J. Phys. Chem. A, 114, 8069 (2010).

12. H.X. Yuan, H.X. Pan, Y.L. Wu, J.-F. Zhao and W.-B. Dong, Acta Phys. Chim. Sin., 28, 957 (2012).

13. Y. Mori, H. Shinoda, T. Nakano and T. Kitagawa, J. Phys. Chem. A, 106, 11743 (2002).

14. L. Huang, W.B. Dong and H.Q. Hou, Chem. Phys. Lett., 436, 124 (2007).

15. M. Wu, W. Shi, Y. Wang, Z. Jiao, J. Wang, G. Ding and J. Fu, Environ. Technol., 30, 191 (2009).

16. J.M. Saveant, J. Phys. Chem., 98, 3716 (1994).

17. M. Arun Prasad and M.V. Sangaranarayanan, Tetrahedron, 61, 3755 (2005).

18. E. Taskinen, Struct. Chem., 11, 293 (2000).

19. I.V. Beregovaya and L.N. Shchegoleva, Chem. Phys. Lett., 348, 501 (2001).

20. K.D. Jordan, J.A. Michejda and P.D. Burrow, J. Am. Chem. Soc., 98, 7189 (1976). 